
Support

\author{
Kathryn Work-Poggi
}

Follow this and additional works at: https://researchrepository.wvu.edu/etd

\author{
Recommended Citation \\ Work-Poggi, Kathryn, "Two Case Studies of Middle School Parents and Their Engagement with Schools \\ Who Participate in Positive Behavior Support" (2018). Graduate Theses, Dissertations, and Problem \\ Reports. 6976. \\ https://researchrepository.wvu.edu/etd/6976
}

This Dissertation is protected by copyright and/or related rights. It has been brought to you by the The Research Repository @ WVU with permission from the rights-holder(s). You are free to use this Dissertation in any way that is permitted by the copyright and related rights legislation that applies to your use. For other uses you must obtain permission from the rights-holder(s) directly, unless additional rights are indicated by a Creative Commons license in the record and/ or on the work itself. This Dissertation has been accepted for inclusion in WVU Graduate Theses, Dissertations, and Problem Reports collection by an authorized administrator of The Research Repository @ WVU. For more information, please contact researchrepository@mail.wvu.edu. 


\title{
Two Case Studies of Middle School Parents and Their Engagement with Schools Who Participate in Positive Behavior Support
}

\author{
Kathryn Work-Poggi \\ Dissertation submitted to \\ College of Education and Human Services \\ at West Virginia University \\ in partial fulfilment of the requirements \\ for the degree of \\ Doctor of Education \\ In \\ Educational Psychology \\ Reagan Curtis, Ph. D., Chair \\ Patricia Haught, Ed.D. \\ Michael Mayton, Ph.D. \\ Jessical Troilo, Ph.D. \\ Eileen St. John. Ed.D. \\ Department of Learning Sciences and Human Development \\ Morgantown, West Virginia \\ 2018
}

Keywords: Parent Partnerships, Education Reform, Family Involvement, Positive Behavior Support

Copyright 2018 Kathryn Work-Poggi 


\begin{abstract}
Two Case Studies of Middle School Parents and Their Engagement with Schools Who Participate in Positive Behavior Support
\end{abstract}

\title{
Kathryn Work- Poggi
}

Positive Behavior Support (PBS) promotes the importance of all staff, school locations, and instructional settings emulating and purposefully teaching the same targeted behavioral expectations. One way to achieve this is to decisively partner with parents and jointly teach positive behavioral conduct and cultivate consistent behavioral expectations across home and school. The purpose of this study was to determine degrees of parent involvement within the confines of a qualitative case study to assess the perceptual nuances that parents experience with their child's middle school using the PBS process. Six parents across two middle schools employing PBS voluntarily shared their perceptions of the benefits and challenges of connecting to their child's school. Results of this study revealed differing degrees of connectedness that are unique to the individual student needs, parental ease in engaging, and the school's effort to establish rapport. Implications for teacher education and parent participation are discussed. 


\section{Contents}

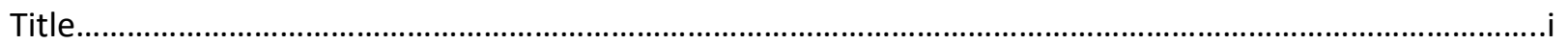

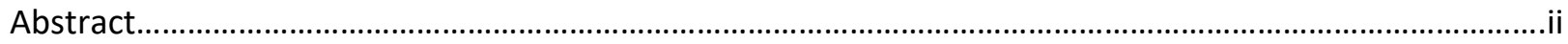

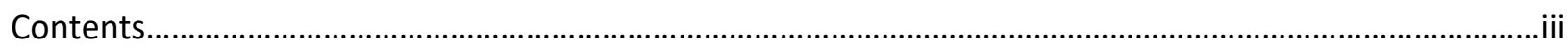

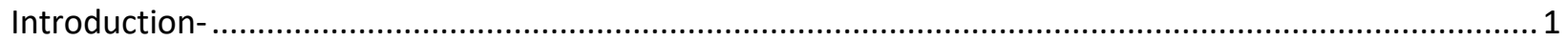

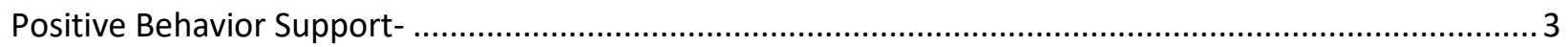

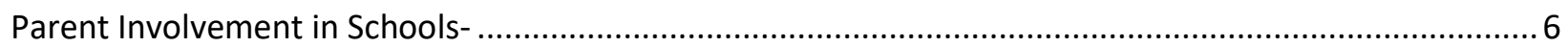

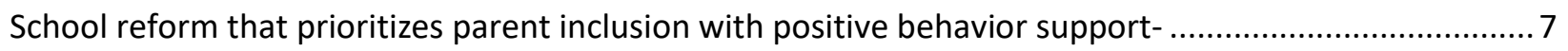

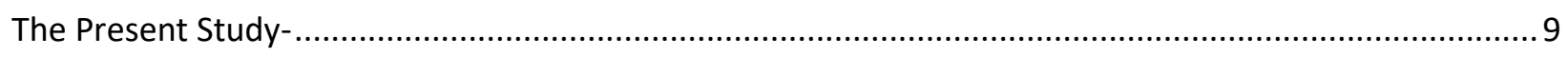

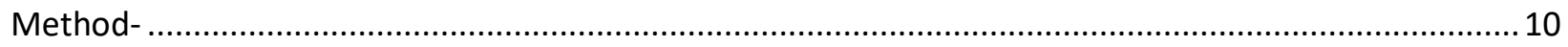

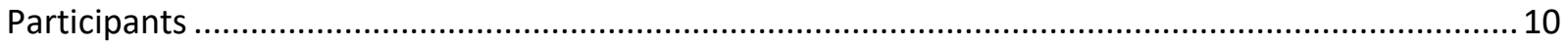

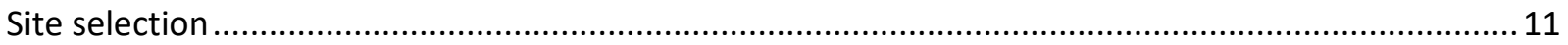

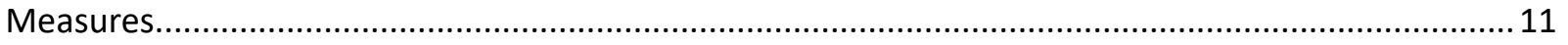

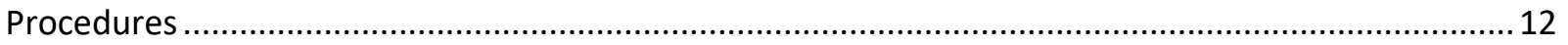

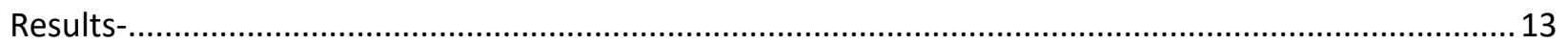

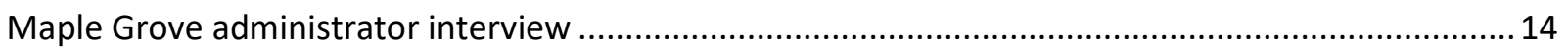

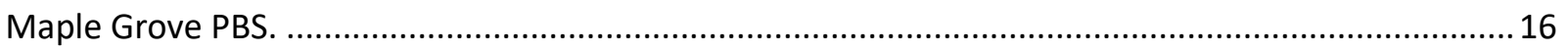

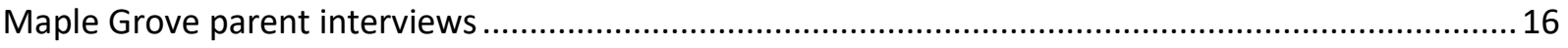

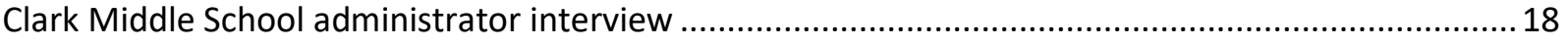

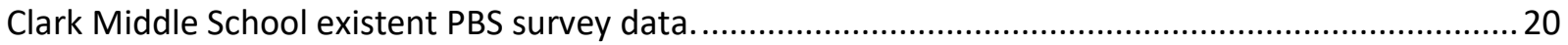

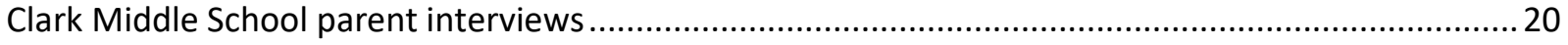

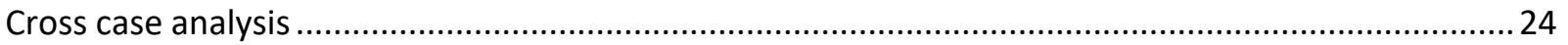

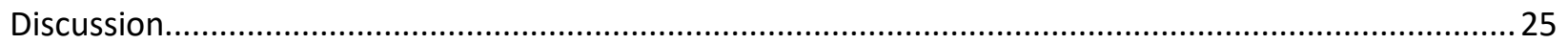

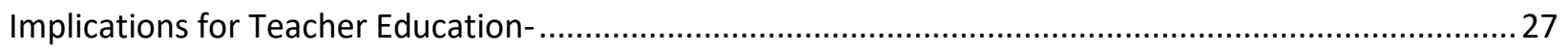

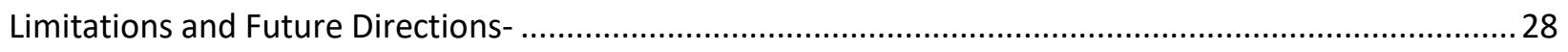

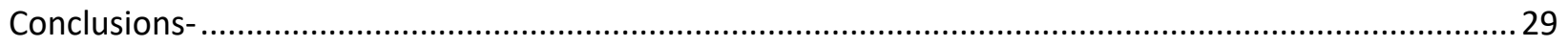

References …

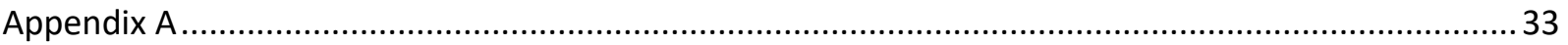

Appendix B … 
Introduction-

Over the past decade parent and family involvement within the school setting as a collaborative partner has become an increasingly sought after level of engagement. According to Jaffee and D'Zurilla (2003) the adolescent middle school years are a critical point of vulnerability where parent and school partnerships are highly influential on student trajectories both within the behavioral and academic realm. Middle school student behavioral and academic performances are intricately connected and vulnerabilities or miscues in one area consistently manifest difficulties in the other. For example, a student that is struggling with reading comprehension has a greater propensity to behaviorally act-out in class due to frustration and difficulties related to completing an assignment. Similarly, a student that has attentional difficulties and is behaviorally disorganized has a higher risk of academic failure related to distraction and the inability to appropriately attend to the task at hand. Supporting students both academically and socially-emotionally at the earliest grade level is of paramount importance to halt and remediate negative trajectories of student response and to augment skill acquisition and content area success. Research by Balfanz, Byrnes, and Fox (2013) echoes the immediacy to remediate student behavioral acting out and indicates the presence of one suspension by ninth grade doubles the chance of the student dropping out. Concerted and purposeful efforts to cultivate behavioral and academic success that includes parent involvement sets the course for positive student engagement and lessens the likely prevalence of chronic disciplinary actions and suspensions. Collective efforts across home and school that espouse the same message increase the likelihood of sustained intervention success and the tendency for students to benefit from continuity and common expectations across settings.

According to Eccles and Harrold (1996) parent partnering in the adolescent year's addresses that critical period of intervention and the best outcomes were noted when parents and schools worked together in facilitating the children's social-emotional and intellectual development. Factors that were noted to highly influence this successful blending were the ease that schools had in connecting with and fostering effective partnering with parents. Further, efforts made by the school to successfully partner and collaborate on the upfront 
made teaming more successful later on when a challenging or worsening behavioral situation manifested.

Educational research consistently interlaces academic outcomes and parental ethnic/cultural backgrounds as a means to cultivate and positively influence advantageous school-based behaviors. Kerbow and Bernhard (1993) directly couple school-based achievements with parent backgrounds and the inherent blending of home-life with academic achievement. Epstein (1984) highlights multiple ways that parents successfully partner with schools while also looking at mitigating factors that either bolster or serve as barriers to authentic collaboration. Focused efforts to relate to the parent in their native language and via their preferred communication style albeit face-to-face, email, or written correspondence yields strong gains in building coveted rapport between parents and schools. Further the notion of hosting home-based or community-centered school gatherings invites increased parental participation and heightens the likelihood of authentic connection with their child's enrolled school.

A school's focused efforts to purposefully link and mutually engage with its parents around the topic of pro-social behaviors is best situated when it is rolled-out systematically across all teaching staff. When additional steps are taken to effectively partner with parents to robustly teach expected behaviors and positively acknowledge their demonstration across home and school heighten sustainment is increased. The multi-tiered system of Positive Behavior Support (PBS) notably teaches appropriate school conduct and pro-social behaviors and affords valuable parent partnering opportunities that prioritizes common messages on behavioral instruction across home and school. Research by Smolkowski et al. (2017) revealed middle schools that employ the PBS model with fidelity commonly prioritize parent involvement and the advantages of common behavioral expectations across home and school. Prevalent existing literature on reciprocal and sustained successful partnering with parents centers around the following three topic areas: PBS, Parent Involvement in Schools, and School Reform that Prioritizes Parent Inclusion in PBS. 


\section{Positive Behavior Support-}

The 2004 reauthorization of the Individuals with Disabilities Education Act (IDEA) and Response to Intervention (RTI) prioritized the utilization of vetted evidence-based practice supports in the general education setting before any restrictive or special education services are considered (Cramer \& Bennett, 2015). Extensions of this work resulted in the development of PBS to help students foster socially acceptable behaviors that best situate them to attend and succeed in their least restrictive instructional settings. PBS is a multi-tiered model that emphasizes prevention and the purposeful teaching of behavioral expectations with the same rigor, preparation, and instructional supports as core academics.

The multi-tiered framework of PBS is comprised of universal and preventative strategies at Tier 1 which includes the installation of positive behavioral instruction that successfully impacts $80 \%$ of the student population. Sample Tier 1 interventions commonly utilized include intentionally acknowledging appropriate student-based behaviors to increase the likelihood of repetition in the future and to also serve as a positive example for other surrounding students. Highly utilized examples of Tier 1 interventions include routines and procedures for classroom conduct and how to successfully access help if a need arises. Tier 2 interventions are commonly described as targeted interventions and are best suited for $10-15 \%$ of the student population that are demonstrating at-risk behaviors and not successfully responding to the Tier 1 universal level supports. Noteworthy, Tier 2 interventions routinely include ancillary small group social instruction addressing emerging areas of concern, such as self-esteem, conflict resolution, and/or coping responses to a family member death or divorce. Lastly, Tier 3 interventions known as tertiary supports are designed at the individual student level and support up to 5\% of the student population who are demonstrating the most risk. These risks include dangerous behaviors and a lack of response to the existing Tier 1 and 2 established interventions. Individualized Tier 3 behavioral supports utilizing Applied Behavior Analytic (ABA) interventions

link back to evidence-based empirical data. Behavioral interventions falling under the auspice of ABA connect to learning theory process and the systematic influence of socially significant behaviors. Further the antecedent- behavior- consequence continuum facilitates the consecutive behavior chain of events that drives the functional reason for the behavior of 
concern (Vargas, 2009). Koegel, Koegel, and Dunlap (1996) point out that all behaviors serve a mutual purpose to either gain access to preferred items/activities or to effectively escape items/activities viewed as aversive. PBS employs these behavior analytic properties and further prioritizes consistencies in interventions and systematized responses across all people, places, and items which makes parent involvement and home-based behavioral partnering a therapeutic ideal. Notable Tier 3 interventions include crisis planning supports for dangerous acting-out and intensive interagency planning to avert risks of self-harm and/or instances of probable school-based violence initiated by the focus student (See Figure 1 Below).

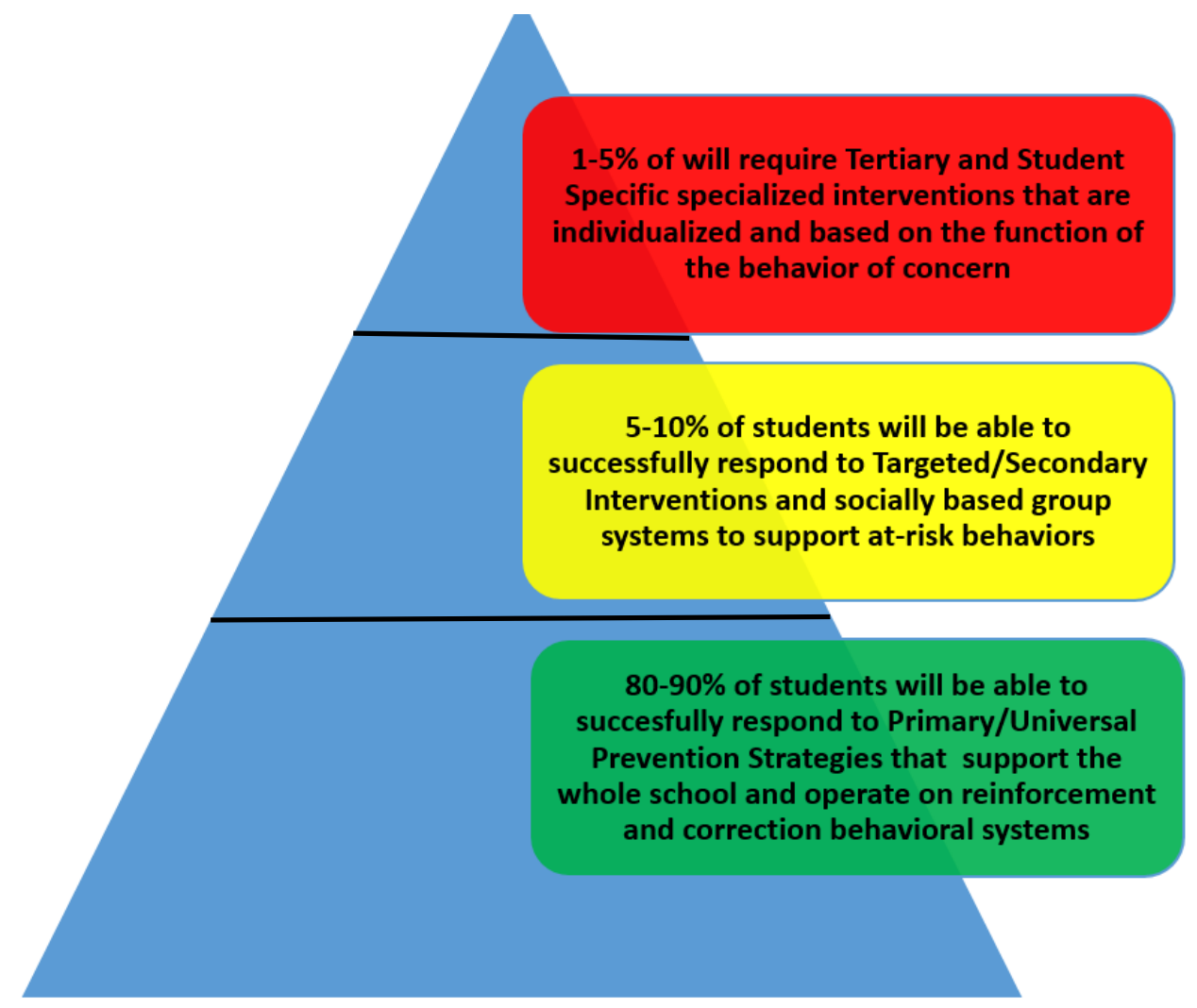

Figure 1. Multi-Tiered Framework of Positive Behavior Supports.

Key paradigm shifts of PBS relate systematically to addressing challenging student behaviors upfront with a preventative lens, much like the public health model described below, as opposed to typical reactive modalities that involve consequence delivery and exacerbated instructional interruptions (Fallon, O’Keefe, \& Sugai, 2012). The public health model similarly prioritizes teaching healthy lifestyle choices in the early years of development as opposed to 
reactive back-mapping efforts after a complication has been detected. Frequent, public health validated behaviors relate to daily exercise, healthy eating, and consistent sleep patterns (Jenkins \& Hutchinson, 1996). Research by Marshall and Mirenda (2002) echoed the preventative benefits of the public health model through the application of these precautionary tactics. This is achieved through successful PBS implementation and purposefully layering parental involvement by means of collaboration and consistent behavioral expectations across the home and school settings. Benefits of deliberate partnering with parents during the early instructional years include prevention tactics and positive behavioral instruction to lessen the development of sustained behavior problems later in life.

Effective behavioral change is grounded in identifying the interconnections between antecedent events related to behaviors and applicable triggers that link to a functional explanation as to why the behavior is manifested. Root causes of behavioral functions and intended reasons why acting out occurs systematically links to the empirical research data found in $A B A$ interventions. The overarching elements of $A B A$ and precisely identifying the functions of a challenging behavior are commonly capitalized by PBS practitioners. Steps to preventively teach expected behaviors and proactively address the functions of the disruptive behaviors which affords more uninterrupted instructional periods and fosters a greater likelihood of academic success.

As previously noted, the adolescent and middle school years are commonly viewed as a critical period for social and academic development in educational research. Mclntosh et al. (2008) further cite this developmental time period as a significant point for social and academic performance indicators. These researchers focused their work on the relationship between academic and behavior variables and how these variables compound each other. Highly akin to earlier cited studies, these researchers noted the impact that behavioral acting-out had on academic performance and instructional success. Additionally, these researchers highlighted significant challenges such as puberty and social pressures that are prevalent in the middle school years that incentivize successful partnering with parents to alleviate school-based acting out and the looming risks of drop-out. Mclntosh et al. (2008) also prioritized the middle school years as plausible turning points for social development and behavioral conduct patterns. 
Results from their study cited strong corollary predictors in 9th Grade for academic performances and $8^{\text {th }}$ Grade for behavior infractions. These findings echo earlier investigations that deem academic skill deficits as precipitating events for chronic behavior problems.

PBS research consistently explores the rates of reported academic skill deficits with the frequency of processed office discipline referral forms for behavioral acting out. Educators and administrators vigilantly examine influences, perceived patterns, and functions of demonstrated behaviors of concern. Results are then used to determine alternative positive behavioral instruction tactics to best support the challenging response and augment the acquisition of the intended academic skill.

\section{Parent Involvement in Schools-}

Educational research consistently explores parent involvement in schools and to what extent their active presence influences academic outcomes. Successful school and parent partnering beckons schools to deeply look at any influential barriers that prevent effective collaboration. A school's fluent understanding of primary spoken languages and ethnic/cultural backgrounds are key considerations to build advantageous school-based parent partnerships. Research by Kerbow and Bernhard (1993) examines the interconnections of school-based achievements and embraces parent cultural backgrounds. Common prioritizations include inherent blending of home-life with school teaching approaches. Similar work from the National Network of Partnership Schools and Epstein (1984) highlights multiple ways to celebrate and positively acknowledge the individuality of each parent's ethnicity and culture as a way to authentically collaborate and respectfully uphold home-based values.

A myriad of existing literature on parental dynamics impacting school partnerships includes elements such a socioeconomic (SES), ethnicity, and extended family members in the home as viable factors (Catsambis, 2001). In addition, Catsambis (2001) also detailed the varied degrees of parent involvement that may be depicted in a school and the range of complexities that could impinge the sense of feeling welcomed and warmly embraced. Minke and Anderson (2005) delved into the vast array of studies examining parent involvement in schools and specifically the pioneered family engagement work investigated by Epstein (1984). These researchers describe a spectrum of parent-school partnerships and highlight two-way 
communication that embodies respect and commitment as the primary factors to effect positive school change. Noted advantageous outcomes included working cooperatively in respectful relationships to achieve a common goal and cultivating an authentic and candid parental voice when discussing district priorities. Requisite steps to propel collaborative partnering forward included proactive training with school staff on facilitation and respectbased communication skills that authentically conveys value in parental participation and the desire for their voiced opinions to permeate across an array of school topics.

\section{School reform that prioritizes parent inclusion with positive behavior support-}

PBS outcomes suggests that fidelity-based behavioral interventions coupled with successful parent engagement result in improved school experiences for students and staff alike. An important aspect of this engagement is a common behavioral voice across home and school. Reported outcomes relating to successful parent engagement include (1) higher student achievement, (2) improved student behavior and attendance; and (3) perceived improved school climate as conveyed by school staff, parents, and engaged students (Henderson \& Mapp, 2002). These noted tenets of positive partnering hold true today. Research by Nunez et al. (2015) depict that effective actualization of these types of outcomes require the same concerted efforts from the engaged school. These efforts also include deliberate steps in school reform to prioritize and sustain authentic parent engagement. Epstein et al. (2002) indicate that effective school partnerships are fostered by schools that view parents as valued partners in the educational process. In addition, precision-based actions on the school's part to promote time, trained staff, resources, and a welcoming space that transcends parent encounters from passing acquaintances to purposeful joint-based school partnering.

Epstein et al. (2002) further expound on six types of parent involvement that bolster parent-school partnerships and the establishment of authentic rapport-based relationships (see Figure 2). Those types are described as follows (1) parenting and support on child/adolescent development; (2) communicating and designing effective two-way correspondence based on the student's progress; (3) volunteering which includes recruiting and organizing parental support; (4) learning at home, which links to creating conducive spaces within the home to 
foster learning and successful homework completions; (5) decision making, which connects to valued parent voice on school-based decisions and situating parents in leadership roles within the educational entity; (6) collaborating with the community, which includes formalizing the integration of resources across home, school, and the community.

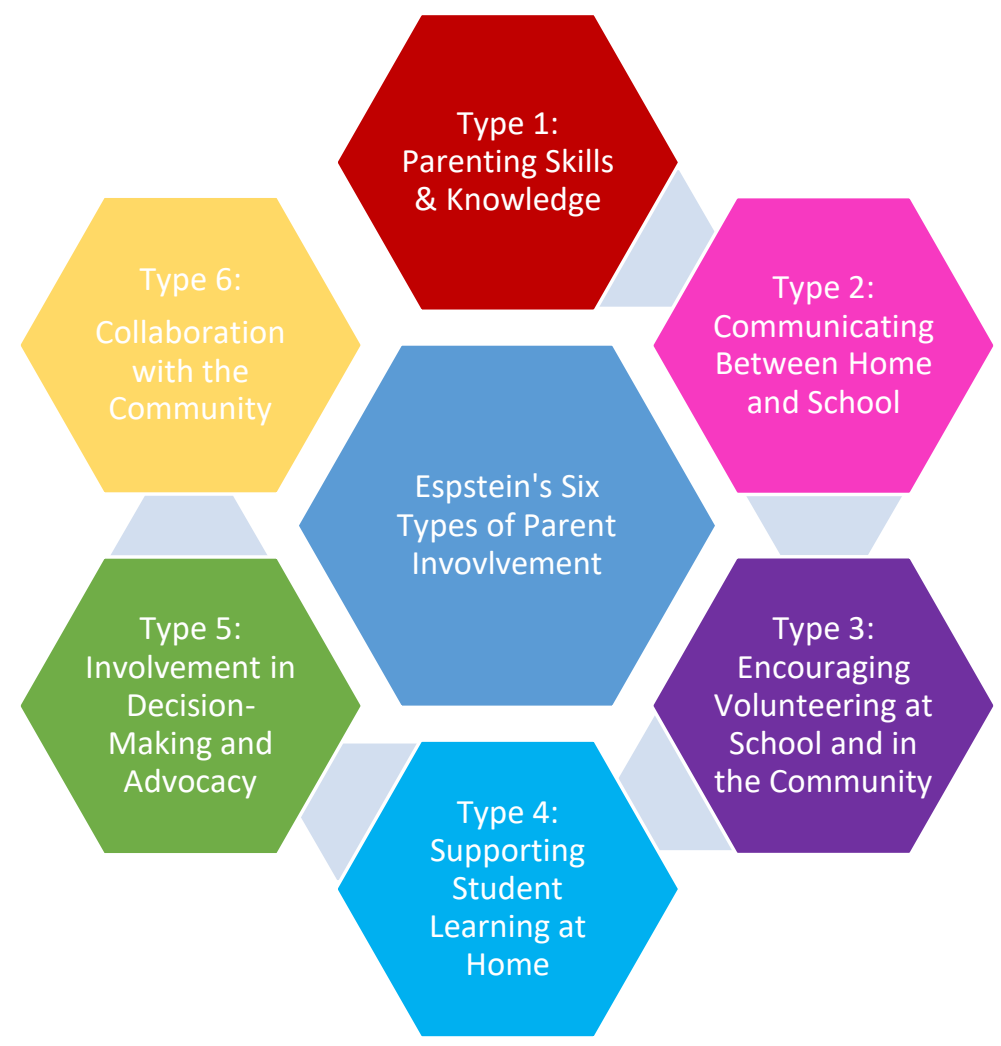

Figure 2. Example of Epstein's Six Types of Parent Involvement.

Similarly with most system change, school reform with parent involvement as a focus is initiated by administrative and overarching school board events. Necessary cognitive and paradigm shifts for schools to authentically engage with parents include purposeful partnering and recognizing their uniqueness as a channel to learn and increase the instructional staff and administrator's overall skillset. Each engaged parent serves as an expert of their own child and also a valued exemplar for future parents on a multitude of cultural, linguistic, and interactive topics. Successful school reform for parent involvement beckons an all-inclusive vantage point that spans far beyond the schools home-base. This collaboration includes home visits and 
convening in common community locales to support families that may have travel restrictions and limited means to attend on-site school events. Securing parent interest and efforts to recruit authentic partnering is bolstered by formal networking events merging evidence-based positive teaching practices with prioritized behavior improvement areas. Novel interactive opportunities and networking outreach events serve as foundational scaffolds to cultivate rapport and invite parent voice and vision on school policies and collaborative undertakings. Informed and cooperative exchanges fuels necessary reciprocity and prolonged engagement to facilitate school climate change that prioritizes sustainment and longstanding partnerships. Such fruitful conglomerates encourage data informed decision frameworks that converge pertinent groups of influence and fitting stakeholders.

To summarize, the existing research lends support for the notion of parental partnering with schools that successfully employ the PBS process. Effectual outcomes hinge on the extent that PBS is fully embraced by all teaching and administrative staff. In addition, parent involvement is prioritized and cultivated as a two-way reciprocally based relationship and school reform efforts are in place to foster sustained parent involvement and deeper degrees of collaboration.

\section{The Present Study-}

The purpose of this study was to qualitatively examine the many ways in which parents of adolescents who exhibit behavioral challenges authentically engage in the PBS process at their child's respective middle school. The parent's true voice and personal reality of their partnering experience was authentically sought with the intent to identify the different degrees in which parents relate to the entire core team with regard to their child's challenging behaviors. PBS core team members included teachers, administrators, counselors and behavioral coaches. Probed measures of past and present types of interactions between home and school included phone correspondence, email updates, personal collaborations, and volunteerism. Epstein's (2005) six types of parent involvement were used as an analytic lens to assess the continuum of parent involvement. 
The following Research Questions were utilized throughout the course of this study:

Research Question 1. How do middle- school parents whose children display challenging behaviors engage with schools who participate in Positive Behavior Support?

Research Question 2. What are the benefits and challenges to engagement for parents?

Research Question 3. How does parents' interpretation of their engagements with Middle Schools using Positive Behavior Support evolve over time?

\section{Method-}

This research operated within the qualitative paradigm using two sites to obtain information regarding parents' engagement experiences with PBS at the school where their child was enrolled. Each participating school was considered a separate case study to permit a deeper understanding of the PBS process and degree of parent involvement within that setting (Glesne, 2003).

Participants. The participants in this study included the parent(s) of three individual sixth graders enrolled in each of the two middle schools utilizing PBS as a behavioral support intervention and the acting building administrator. The participating parents in these case studies were linked to specific middle schools that successfully reached fidelity at the Tier 1 universal level for PBS. The parents were purposefully selected due to their personal experience of PBS within their setting and their ability to best answer the research questions. In Case Site 1, two of the participating parents each had a child receiving Tier 1 support, while the third parent's child was supported with Tier 2 interventions. At Case Site 2, two of the participating parents each had a child receiving Tier 3 support, while the third parent's child was supported at Tier 2. Each building principal, associated with the two case sites, also agreed to participate in a personal administrator interview to discuss their reasoning to initiate PBS within their setting and the individual steps taken to allocate resources to navigate inherent challenges and benefits connected to PBS and purposeful parent partnering within their local site. 
Site selection. Site selection was based on the following criteria: both of the participating middle schools had successfully achieved fidelity at the Tier 1 universal level for PBS and voluntarily were seeking to increase the parent engagement of their adolescents who were at risk for school failure due to behavioral concerns. Furthermore, these two middle schools were chosen by the researcher based on their administration's desire to authentically increase parent involvement in the PBS process. Delving into parental perspectives (which includes their understanding of current practices, priorities, teaching of routines and PBS procedures) can facilitate a paradigm shift to a more interactive and meaningful collaboration between parents and schools. This authentic extension augments the intrinsic benefits that drives parents to partner and emulate the PBS tenets in their own personal home. For the purposes of this study the two schools were assigned the following pseudonyms: Maple Grove Middle School (Case Site 1) and Clark Middle School (Case Site 2).

Both Case Sites involved in this study were located in rural settings in a mid-Atlantic state. Demographics for Maple Grove included approximately 500 students with $98 \%$ of the students being Caucasian. Of the 500 students, $48 \%$ are male and $51 \%$ are female and $45 \%$ receive free /or reduced lunches. The median income of the parents within this site is $\$ 50,074.00$. Demographics for Clark Middle School included 600 students with $62 \%$ being Caucasian. Of the 600 students, $51 \%$ are male students and $48 \%$ female and $37 \%$ receive free/or reduced lunches. The median income of the parents within this site is $\$ 30,422.00$. This particular school is situated in a more economically challenged area.

The variances of each of the middle schools and student demographics aligned with Creswell's (1998) thoughts on qualitatively exploring multiple systems or cases over time through detailed in-depth data collection that involve multiple sources that are rich in context. Parent volunteers for this study were recruited via an invitation to participate that was posted in each middle school's central office. The qualifying parent participation criteria were willingness to uphold common behavioral expectations at home and first-hand experience with PBS implementation.

Measures. Three data collection methods were used throughout the course of this study: analysis of an existing PBS survey completed annually by teaching staff measuring the 
critical features of PBS implementation within their site, semi-structured interviews with each middle schools' administrator and the three parent volunteer participants from each case site, and document reviews of the written PBS correspondence between home and school. Two of the anonymous Likert-based questions within the anonymous survey related to teacher perception of parent involvement on PBS priorities and their inclusion on decision-making activities to best situate the positive climate for learning and positive interactions across the school. The wording for the two analyzed survey items were as follows: (1) Significant family and/or community members are involved when appropriate and possible, (2) School includes formal opportunities for families to receive training on behavioral support/positive parenting strategies (retrieved from: https://www.pbisapps.org , 2017). Five semi-structured interview questions were utilized during the administrative interviews at each case site to garner the rationale and priorities that spurred PBS implementation within each respective middle school building (See Appendix B). The parent interviews consisted of seven open-ended questions inviting parents to describe the ways they participate and remain informed on PBS within their child's middle school and their perception of any benefits and/or challenges to this engagement (See Appendix A). Emergent thoughts and themes were captured via analytic memos and served as an extra narrative level to intermingle interview provided details and the presence of interpretative understanding.

Procedures. IRB approval was secured prior to any data collection. Data in these case studies were triangulated and analyzed across the audio-transcribed interviews, document reviews, and the analytic memos capturing this researcher's insights and thoughts that occurred naturally throughout the study. Research in this study emulated what Merriam (1998) described as a simultaneous activity where data collection and analysis of parent responses were conducted in an ongoing manner to identify thematic commonalities. Patton (1990) defines qualitative data analysis as "a painstaking process requiring long hours of careful work going over notes, organizing the data, looking for patterns, checking emergent patterns against the data, cross validating data sources and findings, and making linkages among the various parts of the data and the emergent dimensions of the analysis" (p. 379). A case record was developed for each of the two case studies which included interview transcripts, coding of 
common categories, and identified links to concepts connected to the review of literature. In addition, a comparative coding analysis was completed to identify patterns and themes across case studies that highlighted parental participation, types of involvement, experiences, impressions, and the presence of any frustrations. Coding and analysis of repeating themes emulated Merriam's (1988) comments "clustering as a tactic to group things that seem similar" (p. 149).

The present study used an extrapolation of all the data in an effort to identify connections and varying nuances and also examined common themes that were relayed via the social and physical artifacts collected at each case site. Epstein's (1984) six types of parent involvement operated as an analytic lens for this study and prioritized areas of open coding were used to label concepts and categories that aligned with demonstrated parent participation in each of the six types of parent involvement (See Figure 2). Further, a "metamatrix" was constructed to illuminate categorical patterns and to facilitate higher level analysis (Merriam, 1998). The probed administrative interviews were included in the analytic coding to identify instances of the same six types of involvement in the administrator's rationale to implement PBS at their respective site. Interview transcripts were coded and grouped based on the review of the literature and aligned with the research questions. Trustworthiness and rigor was maintained through the utilization of "member check" (Schwandt, 2001, p. 195). Member checks are defined as member validation and were used as validation and accuracy confirmations across the different site participants. Utilization of this tactic included reflective listening and narrative summaries throughout the course of the interviews to permit the parents to affirm that the captured notes and insights accurately reflected their views, feelings, and experiences.

\section{Results-}

The qualitative results from these case studies yielded varying degrees of parent engagement that echoed Epstein's (2002) continuum of involvement ranging from passive engagement to deeply vested weekly instances of active engagement. The Center for Disease Control (CDC. 2015) defined parent engagement as parents and school staff working together to support and improve the learning, development, and health of children and adolescents. The 
CDC further recommended the cultivation of positive family partnering and engagement due to its role in cultivating positive protective factors and natural supports that bolster student success from both an academic and behavioral lens. For the purpose of this study parental active engagement with the middle schools included ongoing verbal face-to-face interactions, phone conversations, email correspondence, impromptu visits to the school, and regular instances of volunteerism. Examples of passive engagement included PBS updates being relayed via their child at the conclusion of the school day, checking their child's backpack intermittently for recognition/acknowledgement tickets received throughout the week, and occasionally checking the district's website and social media platforms for PBS updates.

Maple Grove administrator interview. During the course of the administrative interview the prioritization of school and parent understanding of PBS was paramount. Voiced concerns of student behavioral acting out and inconsistencies across locations created a fractured and highly disorganized learning environment. In an effort to reduce behavioral infractions and academic failure this administrator adopted and self-initiated PBS interventions as the vehicle to address systemic student behavioral concerns. For the purpose of this study behavioral acting out included disruptive behaviors such as, but not limited to, verbal defiance, refusals to complete class work, and disrespect toward teachers and other students. An analytic memo captured during the course of the five semi-structured interview questions conducted with this administrator (See Appendix B) revealed ongoing frustration over noisy and disorganized learning environments. Also, heightened concern over the number of office discipline referrals being sent to the office caused angst from both an administrative operational lens and also at the student level regarding the cumulative impact of chronic interruptions to instruction.

The incorporation of PBS within Maple Grove and the administrator's decision to implement was reported to be a resoundingly well received notion. Staff buy-in and parental involvement was a reported next step extension and was demonstrated by this administrator's quote stating "PBS and parental involvement made perfect sense and triggered more good things that staff reported back to me on a regular basis". Further this administrator shared open comments about "the kids understanding the procedures and PBS expectations did the trick and has completely changed the culture around here". Noted connections and links to the 
Epstein (1984) types of parent involvement are captured in the following graph and depict the number of communicated responses that directly connect to Epstein's (1984) six types of parent involvement.

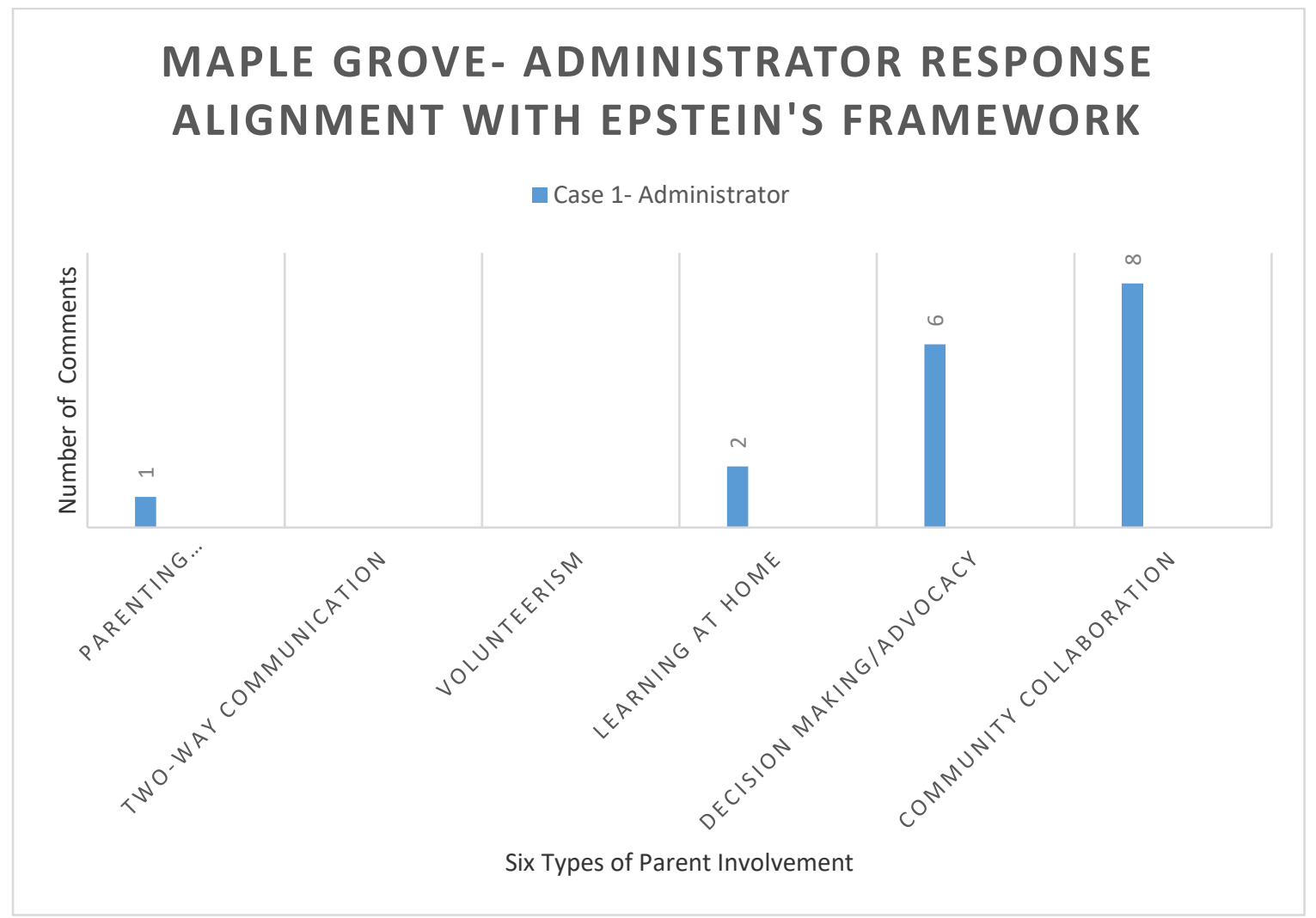

Figure 3. Maple Grove Administrator Response Alignment with Epstein's Framework

Analysis of the coded responses and overarching themes revealed repeated connections to Epstein's (1984) analytical framework with prioritized areas of systemic and organizational expansion within types 5 and 6 relating to Decision Making/Advocacy and Collaboration with the Community. Targeted roll-out of those expanded types of parent involvement included having a parent serve on the PBS core team and outreach plans to secure grants and community funding for prioritized PBS incentives. A resounding take-away from this interview was the administrator's enthusiastic comment that it is "pretty cool to layer PBS into their family engagement efforts". 
Maple Grove PBS. Maple Grove's full staff annually completes the anonymous qualitative survey designed to measure in-place critical features of PBS within their site. Two of the existent questions link directly to efforts to purposefully engage parents within the PBS process. Analysis of these two items revealed $92 \%$ of their staff felt parents were involved in PBS and $67 \%$ voiced the presence of training opportunities to extend behavioral learning to the home context. These responses speak to the power of perception and also present powerful learning opportunities to further purposefully engage with parents and creatively include them in teaching opportunities connected to PBS within their school site.

Maple Grove parent interviews. Qualitative exploration was used to determine the parents' varying levels of experiences and degrees of engagement within the PBS process using the seven semi-structured questions (See Appendix A). A preliminary analysis, linked to Research Questions 1 and 2, was performed to determine if and how the parents engage with their schools around the topic of PBIS and whether they experienced any benefits and/or challenges. One enthusiastic response from Maple Grove parent revealed a routine occurrence of her son "coming home from school super happy with his ticket and that he loves to keep them and is very proud of how many he earns". This parent voiced appreciation that the school purposefully teaches positive conduct and said "it is nice to know that the teachers notice that the students are following the PBS expectations". Another Maple Grove parent shared a comment that echoed Koegel, Koegel, and Dunlap (1996) that all behaviors serve a purpose and students notice what gets reinforced and what does not. This parent also shared resentment by her son's comment that "so and so got a golden ticket today for something I did the same way yesterday and wasn't awarded". She further retorted her efforts to teach the age-old adage "life isn't always fair and not everybody gets a prize". Nonetheless, these observations align with Fallon, O'Keefe, and Sugai's (2012) comments that PBS interventions need to be purposefully taught and uniformly upheld across all staff and in all locations to maximize consistency and to sustain student interest and buy-in.

Further probing questions on the benefits or challenges linked to Research Question 2 revealed a direct link to Epstein (2002) "supporting student learning at home". This is further demonstrated by a Maple Grove parent's candid description of modeling social kindnesses such 
as "please, thank you, respect your elders and teachers, and how great it is that the school is backing-up what I am teaching at home". The parent further described the school's PBS instruction as a "more fluid process and how it is not just the parents preaching this good behavior stuff". Noted connections and links to the Epstein (1984) types of parent involvement are captured in the following graph and depict the number of communicated responses by the Maple Grove parent participants that directly connect to Epstein's (1984) six types of parent involvement.

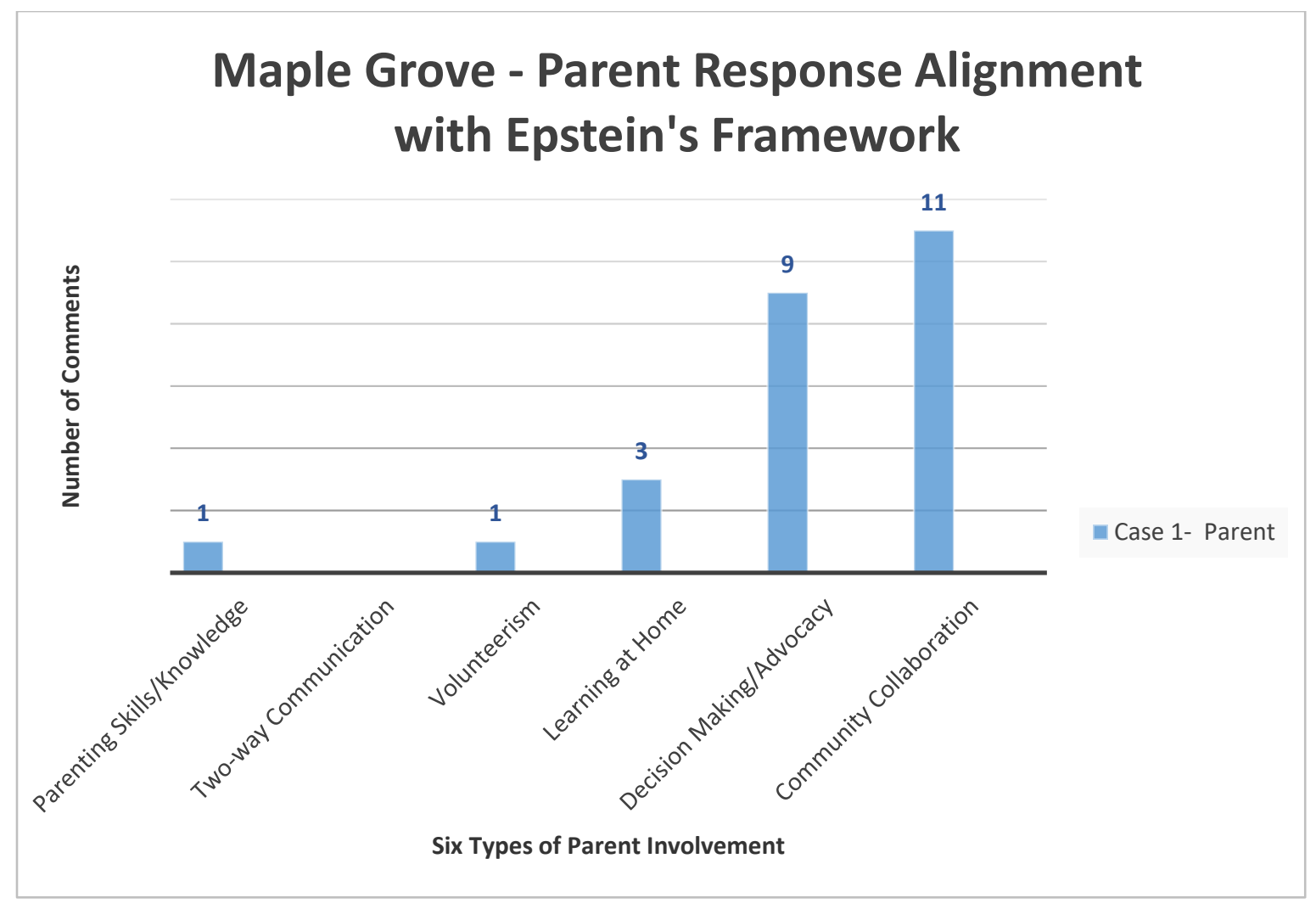

Figure 4. Maple Grove Parent Response Alignment with Epstein's Framework Interestingly the reported types of involvement shared by the Maple Grove parents revealed congruence with priorities conveyed by the building administrator connected to Involvement Types 5 and 6 relating to Decision Making/Advocacy and Community Collaboration. Multiple nuances of plans for sustainment and efforts to bolster funding and donated supports for PBS implementation were shared along with ideas to grow their PBS efforts to include more parents and surrounding community members. 
Research Question 3 probed if the parents perceived an evolution of engagement with their school around the topic of PBS and if that interpretation caused them to feel more connected with their school throughout the passage of time. Open coding and analytic theme analysis of the three parent interviewee responses at Maple Grove did not reveal the presence of a connectedness evolution and increased involvement as a result of PBS. Each parent voiced interest in the PBS happenings at their child's school and shared joy over their child's excitement with being acknowledged, but these positive climate endeavors did not burgeon an incentive to overall increase involvement and active participation in scheduled onsite PBS and school-based events. One parent at Maple Grove voiced "I like this school very much and intend to continue to volunteer at the schoolwide events". She further stated "I feel sincerely connected here and want to help other parents that have students here even after my son moves onto the high school". Each of these statements emulate connectedness, but do not fully convey the reason why and whether PBS triggered the evolution of being positively attached to her son's school. An analytic memo captured during this interview related to the touching sentiment of the parent feeling very welcomed within Maple Grove and that she felt her volunteer efforts via PTO and ancillary school events were highly appreciated. Quotes from her comments on feeling welcomed included the following: "I just want to be here and visit the school for the different activities that happen throughout the year" connects to Glesne's (2003) comments on trust and building relationships.

Clark Middle School administrator interview. The administrator the second case site was engaged in the same five semi-structured interview questions (See Appendix B) to glean understanding of their rationale to launch PBS and the impetus of need that spurred the necessary allocation of time and resources connected to implementation. The administrator at Clark Middle shared a different on-boarding approach and indicated that this initiative was not initially his idea and that the district Superintendent and school board members initiated this formal positive climate change. He further voiced needs and programmatic concerns related to increasing conflict across both students and staff and concern over safety and necessary instructional control. An analytic memo captured during the course of this administrative interview related to visible concerns over physical confrontations and the risk of staff retention 
due to chronic behavioral challenges that prevented successful instructional delivery on a daily basis.

The Clark Middle School administrator explained that once he was given the direction to implement PBS it was a "grass roots effort and I prioritized time and self-funding tactics to complete the necessary staff trainings and get everyone up to speed on the building's PBS principles". He further stated "it's all the little things that we constantly do and the support across the different PBS tiers that change and effect the culture and the behavior of everyone across this building". The analytic lens of Epstein's (1984) Six types of involvement were again utilized to capture themes and repeated categories of engagement across the administrative and three parent volunteer interviews at this case site. The following graph depicts the number of communicated responses that directly connect to Epstein's (1984) involvement types (See Figure 2).

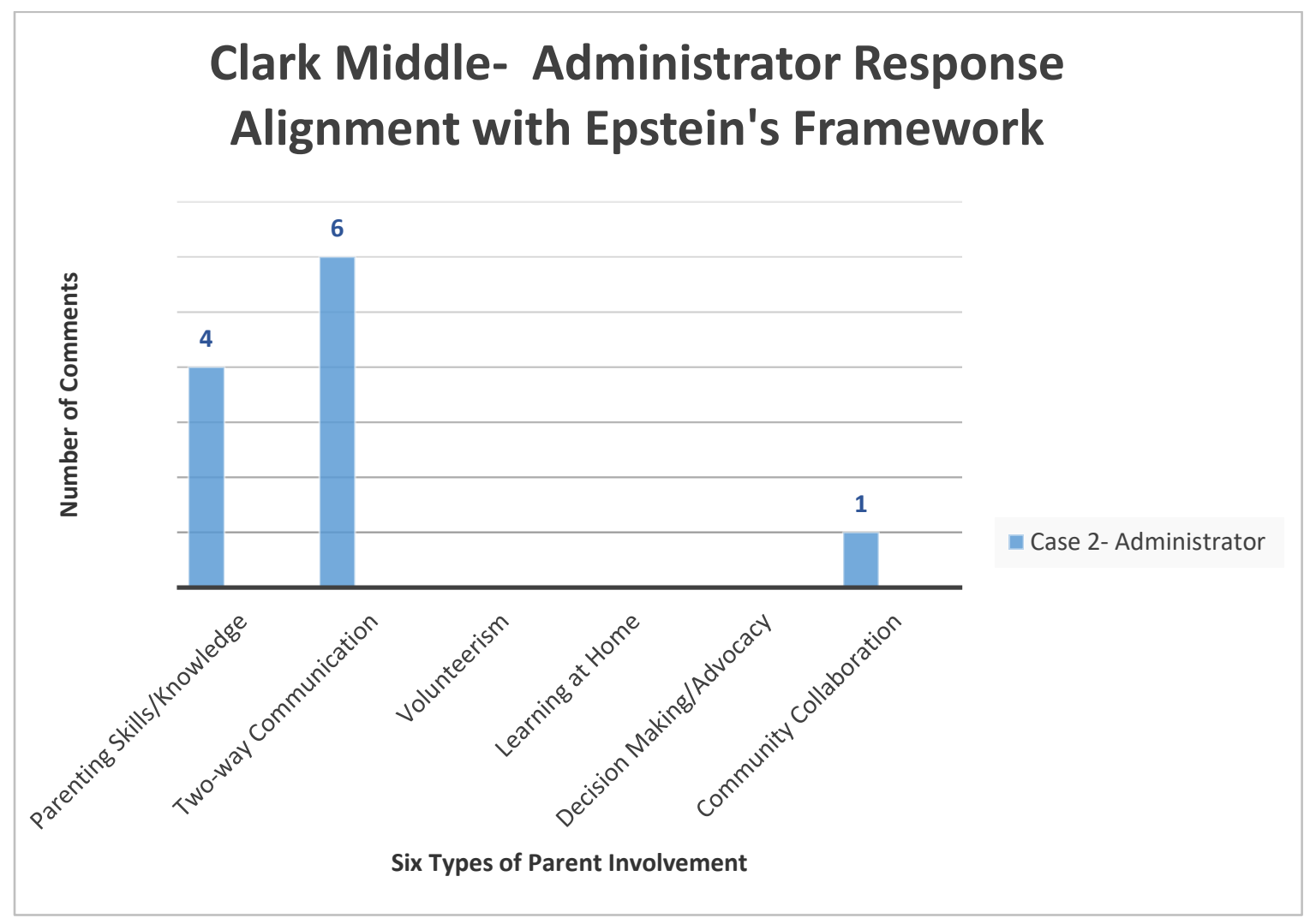

Figure 5. Clark Middle School Administrator Response Alignment with Epstein's Framework 
Analysis of the coded responses and overarching themes at Clark Middle revealed repeated connections to Epstein's (1984) analytical framework with prioritized areas around parent support and the importance of reciprocal two-way communication connected to Types 1 and 2. Continued prioritized support in these areas relate to supporting consistent behavioral messages and expectations across home and school and including outside behavioral health team members on any targeted interventions. A powerful take-away captured during this administrative interview included "the importance of social and emotional learning and the pay-off in finding the best fit for what our students and families need".

Clark Middle School existent PBS survey data. Similar to Maple Grove, Clark Middle School's full staff annually completes the anonymous qualitative survey designed to measure the in-place critical features of PBS within their site. Analysis of the two items assessing efforts to purposefully engage parents in the PBS process and efforts to train parents on the building's PBS tenets revealed the following percentages respectively $40 \%$ and $10 \%$. This researcher was struck by this disparity, because qualitatively each of the parent respondents at Clark Middle School relayed more frequent school drop-ins and purposeful individualized connections than the probed parents at Maple Grove. An analytic memo during the analysis of these existent qualitative survey responses connected to the immense power of perception and the suggested gap between PBS steps to authentically engage with affiliated parents and the building level internal belief of what was actually transpiring. Additionally, I imagined a crucial teachable moment to ensure that everyone is on the same page and able to acknowledge the good things that are in place and the full continuum of PBS scale-up as it relates to parent involvement.

Clark Middle School parent interviews. Qualitative inquiry was conducted to determine parent connectedness and engagement with the PBS process at Clark Middle School using the same seven semi-structured interview questions (See Appendix A). The Epstein (1984) framework (See Figure 2) was again used as the analytic lens to answer the probed research questions. Research question 1 assessed how parents engaged stay informed on PBS within this site. Each of the three parent participants at Clark Middle School revealed routine back-pack checking and daily updates from their child. Further, a noteworthy parent from Clark Middle School shared "it's nice to hear from the school about good stuff and not just when it's 
something bad". Expansions of this parent comment included "it causes the kids to think before they do something that maybe they shouldn't".

A similar answer from another parent commented on the power of communication and how she appreciates staying informed. A poignant example of this parent's thoughts includes the following: "PBS has become a culture in the school and I can see the buy-in and philosophy growing across students and staff". Probes for examples on how or why she felt the buy-in and philosophy was growing revealed an increase in personalized email correspondence, face-toface interactions with most of her son's engaged teacher's, and efforts to collectively team on individualized behavior interventions with outside behavioral health agency staff. This parent further enthusiastically stated “the school began to generate group emails for my son's behavioral team and that included his home-based behavioral therapist, all four of his regular education teachers, and all of his special education teachers, the guidance counselor, and the principal". A sense of relief was keenly visible in this parent's adjusted posture and her apparent appreciation of the school's willingness to work together to best support her son's ADHD and generalized anxiety diagnosis. Further elaborations from this parent included the confidence that she could stop in and meet the school team in person when sensitive subjects required extra face-to-face support which she described as "underlying tones and needs that can't be read when looking at an email".

Research Question 2 probed instances of benefits and concerns associated with PBS. A male participant affiliated with Clark Middle School relayed his concerns over bus behaviors and the need to "be consistent with expectations on the bus because needs and safety issues often arise outside of the school and when the students are less supervised". When probed further to describe how this was a concern he shared "communication needs to be looped back to the bus drivers, discipline can be good at home and now we have the school doing this stuff, but the bus can be a totally different and unconnected experience". Further probes on other less than positive experiences with PBS echoed Jaffee and D'Zurilla's (2003) comments on behavioral challenges in the middle school years. This was further exemplified by a Clark Middle School parent who stated that her son "can really test her patience at home and she is now trying to tweak rules at home to reinforce and be on the same page as the school". The 
following graph depicts the number of communicated responses captured across the three parent interviews at Clark Middle School and how they directly connect to Epstein's (1984) six types of parent involvement (See Figure 2, Page 11).

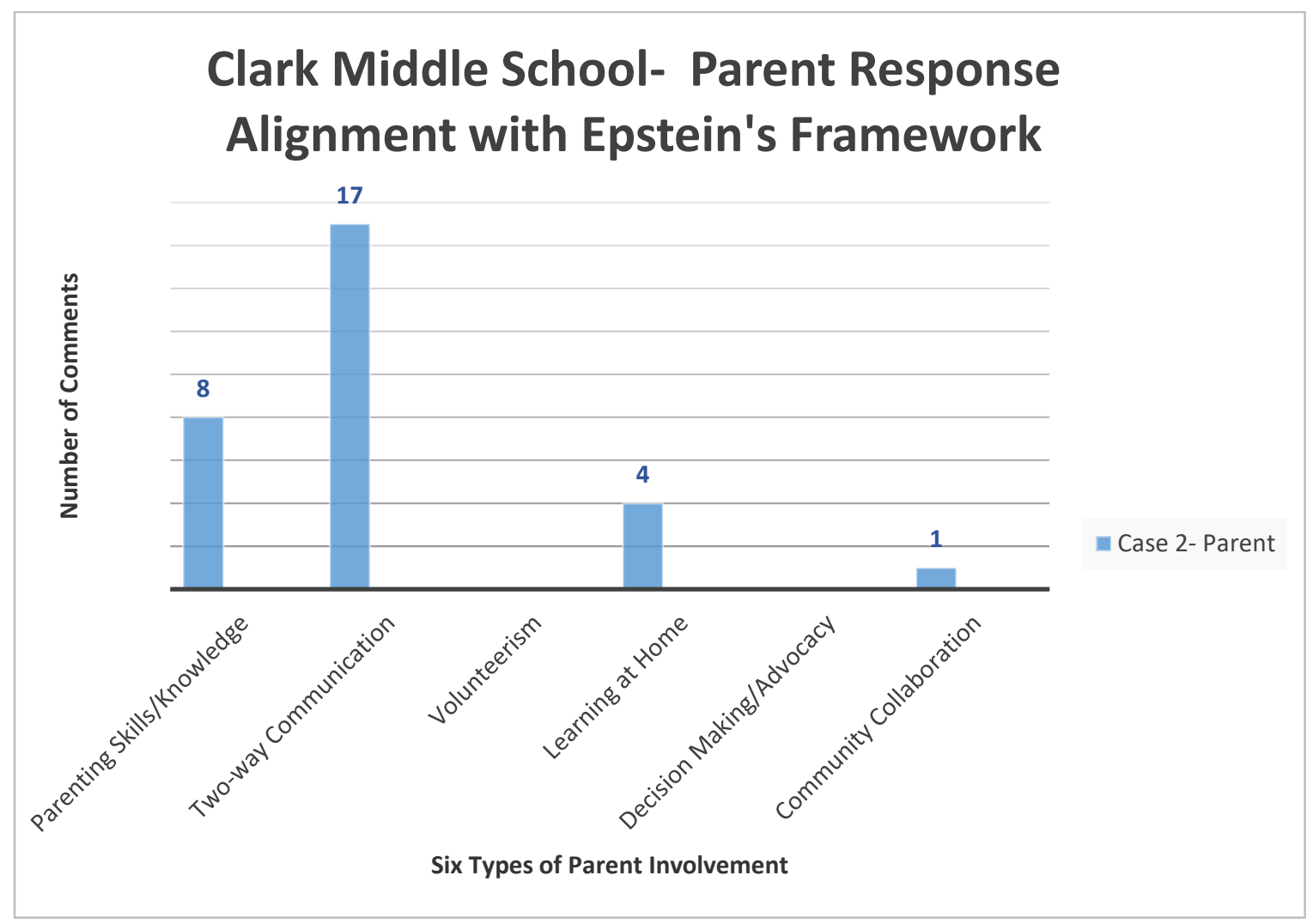

Figure 6. Clark Middle School Parent Response Alignment with Epstein's Framework

Similar to cross analysis of administrator and parent responses at Maple Grove the provided parent interview answers at Clark Middle School overwhelmingly aligned with what the building administrator described as priorities with parent involvement areas within Type 1 and Type 2 focusing on Parenting Skills/Knowledge and Two-way communication between home and school. Undoubtedly, the reported and open coded responses revealed Type 2 involvement and robust communications across home and school as their strongest link to engaged parents.

Research Question 3 delved into the presence of deeper relationships with the school and an evolving perception of connectedness as a result of PBS. Candid sharing and open discourse throughout the parent volunteer interviews revealed a palpable connection between 
parents and school staff at Clark Middle School. Instances of appreciation linked to ongoing compassionate support to a child that had lost a parent and over-and-above efforts to keep school-based teams and ancillary therapists/ behavioral health partners connected and on the same page to ensure intended intervention consistencies. A poignant example of this included a father's description of weekly lunches that the counselor coordinated to extend support and empathy for grief associated with losing a parent. This parent further shared "they are helping him in so many ways and helping him to be a compassionate caring child so he can also help others". An analytic memo gathered across each of the Clark Middle School parent interviews related to awe-struck impressions of collegiality and unified team work across a myriad of behavioral need areas and family dynamics that were as unique as snowflakes. A true heartbased connection was undeniable and repeatedly conveyed by the parent participants as they opened up and shared personal nuanced response.

Albeit these parent connections and personal stories emanate true partnerships and long-sought after degrees of involvement, none of the stories or details shared hinged solely on PBS as the catalyst for convergence. Again, the degrees of connectedness and any presence of an evolution probed in Research Question 3 could not be adequately answered by the coded and cross analyzed parent responses. 
Cross case analysis. Repetitive patterns of voiced priorities for parent involvement across administrators and the building specific parent volunteers revealed commonalities and alignment across Epstein's Six Types of Parent involvement. Overarching codes gleaned from parent interviews across both Case Sites are depicted in the following table using a meta-matrix as described by Mirriam (1998).

\section{Table 1}

Overarching Codes Across Case Sites

\begin{tabular}{|c|c|c|c|}
\hline Epstein Involvement Types & Code Type & $\begin{array}{c}\text { Case Site } \\
1\end{array}$ & $\begin{array}{c}\text { Case Site } \\
2\end{array}$ \\
\hline Type 1 & Code 1- Parenting/family support & 1 & 5 \\
\hline Parenting Skills/Knowledge & Code 2- Healthy resource sharing & 0 & 3 \\
\hline Type 2 & Code 3- Academic problem solving & 0 & 2 \\
\hline \multirow[t]{2}{*}{ Two-way Communication } & Code 4- Social emotional problem solving & 0 & 11 \\
\hline & Code 5- Knowledge sharing on school resources & 1 & 4 \\
\hline Type 3 & Code 6- Classroom volunteer & 0 & 0 \\
\hline Volunteerism & Code 7 -School resource volunteer & 1 & 0 \\
\hline Type 4 & Code 8- Homework support & 2 & 1 \\
\hline Learning at Home & Code 9- Student goal planning & 1 & 0 \\
\hline Type 5 & Code 10 - School reform & 1 & 0 \\
\hline \multirow[t]{2}{*}{ Decision Making/Advocacy } & Code 11- Academic advisory & 4 & 0 \\
\hline & Code 12 - School safety advisory & 4 & 0 \\
\hline Type 6 & Code 13 -Health and recreation & 3 & 0 \\
\hline \multirow[t]{2}{*}{ Community Collaboration } & Code 14 Fundraising and donations & 4 & 1 \\
\hline & Code 15 Music, art, and drama events & 5 & 0 \\
\hline
\end{tabular}

Document reviews and written correspondence across both case sites included a plethora of electronic communications involving district social media platforms, check-in's on district informational apps, and also monitoring blast emails and newsletters generated by the building administrator. A voiced concern from four out of six parents across both sites demonstrated an over reliance on electronic media to communicate with parents. Participant comments revealed many instances of families, at the schools, not having access to personal computers or their own electronic devices. Thoughtful suggestions to remediate this included 
"mailing out flyers or postcards and doing updates through the PTO to keep all parents in the loop".

\section{Discussion-}

Auerbach and Silverstein (2003) endorse qualitative studies as a means to look at what is "left out and what assumptions need to be challenged" (pg. 15). Data triangulation from this study revealed overwhelming benefits linked to purposefully partnering with parents around the topic of PBS implementation. Common language and purposefully teaching behavioral conduct with the same rigor as academics resulted in parent reports of student pride and interest in doing well at school and being awarded for upholding the PBS tenets. The behavior and academic connection described by Jaffee and D'Zurilla (2003) was emulated by reducing discipline infractions and principal office visits through purposefully teaching positive behaviors. Cramer and Bennett's (2015) thoughts on using the PBS philosophy as an overarching framework to set the positive tone for instruction was also visibly depicted across both case sites via dedicated time for behavioral instruction and creative incentive systems to positively reinforce the appropriate behaviors of their engaged students.

The notion of parent partnering around the topic of PBS was a prioritized research question within this study, resoundingly both parents and administrators voiced value in authentic engagement and collaborative partnering. Targeted PBS interventions across both sites spanned the full continuum of supports with difference in need and depth of collaboration being keenly shared throughout the parent interviews and their personally shared experiences. The primary interventions and needs reported from Maple Grove depicted two students requiring Tier 1 supports relating to mild classroom management behavioral needs and one student receiving supports at Tier 2 to assist with confidence and peer socialization. In contrast, the parent stories associated with Clark Middle School revealed two students requiring Tier 3 personalized supports related to necessary grief/coping responses and another student working through complex mental health and anxiety derived challenges. The third student associated with Clark Middle School was supported at the Tier 2 level with socialization supports and behavior contracts to support active student engagement in the classroom. Cross-case analysis revealed substantial efforts from both middle schools to remain actively engaged and involved with their affiliated parents, but vastly contrasted needs when considering the depth of needs 
and degrees of supports required to facilitate a successful school experience. Clark Middle School navigated densely more complicated and involved behavioral challenges than the ones that were described at Maple Grove. The associated interventions aligned with Tier 2 and Tier 3 described at Clark Middle School require extensive data and intervention management in comparison to the strategies described as in place at Maple Grove.

As cited earlier by Auerbach and Silverstein (2006) it is important to view qualitative studies through the lens of what is revealed and uncovered and also just as importantly what is missing and still left unanswered. The parent respondents in this study communicated varied degrees of connectedness and their feelings of being embraced by the PBS core team and administrators. Although this feeling is highly coveted and one that is typically sought out through the course of PBS implementation, it is not yet clear from the research results if these feelings of connectedness resulted from the framework and tenets of PBS or at a more deeper level resulted from the people and the actual implementers of the intervention at the respective school sites. This lack of definitive clarity speaks to the heart of connectedness across people and the common goal of surrounding a student with the natural supports to best situate their success. Within these two case study sites PBS appeared to be the vehicle to collectively unify parents and school around positive behavioral conduct. The Epstein (1984) six types of parent involvement was utilized as an analytical lens in probing the research questions across the two case sites. A cursory scan of the six types of parent involvement as described by Epstein (1984) could cause a reader to assume that the later types of involvement (example Types 5 and Types 6) are indicative of heightened parent involvement and more success with effectively engaging with the associated parents. However, results from this study did fully not align with that mindset and did not depict an evolution of connectedness. Undeniable success was noted across both case sites with regard to parent outreach and efforts to keep parents keenly informed on PBS happenings and prioritized school events. Maple Grove demonstrated long-range planning and sustainable procedures to support organizational and systemic school operations within both the academic and behavioral realms which is highly commendable and will likely serve them well as future school years come to pass. Clark Middle School on the other hand presented a deeper more palpable degree of partnering that emulated a full wrap-around 
intent of the family and child to jointly navigate and positively support the inherent social and academic needs that are requisite for successful school performance and academic success. These findings and perceptional take-away were an unexpected outcome of this study and further endorsed the paradigm shift of PBS and the prioritization of preventatively and actively supporting behavioral needs on the upfront while cultivating healthy social and emotional supports to best augment later academic area skill acquisition.

\section{Implications for Teacher Education-}

Results from this present study reveal the power of rapport and purposefully partnering with parents around the topic of PBS and pro-socially derived behaviors. Although, many modalities for communication exist to keep parents informed, results from this study suggest the best level of engagement stems from authentic connection and trust that all parties are working as a team. Many schools aspire to bridge the gap between their present parent engagement practices and that which is espoused by Epstein et al. (2002). Cognizance that true parent partnering spans a continuum of engagement levels and results from cumulative trust and positive interactions is imperative to the process and the sustainability within the school. Students often follow the lead of their parents and emulate the perceived impressions that their family member conveys. Investing energies to effectively engage with parents at the onset of the school year permits the coveted continuum of engagement to take root in the requisite foundation of trust and rapport.

Implications for teacher education should include professional development focusing on parent connectedness. Epstein's Six Types of Parental Involvement (2005) are recommended as a starting point for learning. Professional Development should further be tailored to needs conveyed by a gap-analysis identifying where on the continuum of parent involvement the teacher is presently operating and how application of that type is being manifested in their instructional setting. Individual nuances and needs that arise from teacher's self-reflection on present levels of parent engagement could foster the incorporation of specific Professional Learning Community (PLC) discussions and workgroups within participating PBS buildings. Conversely, the inclusion of a parent member within the building level PBS core team is 
recommended to facilitate joint planning and agreement on prioritized behavior tenets. A parent's voice at this table could operate as a needed lens for realistic priorities and viability of expectations. Additionally, a parent's presence within PBS planning meetings further bridges the divide between home and school and could foster desired parent buy-in on targeted interventions to address behavioral instances of concern. Ongoing efforts and assessment should be conducted both formally and informally to measure the degree of family involvement that is occurring and whether these changes are direct outcomes of the professional development and PLC activities. Long range planning and school improvement action plans should also prioritize the inclusion of parents in all school based events and consistently work to augment the impact of their voice across all targeted initiatives.

Acknowledgement of family cultural backgrounds and efforts to respectfully connect could be extended by the incorporation of a district family liaison that actively works to meet parents where they are regarding cultural beliefs and language of origin. Catsambis (2001) recommends welcoming parent collaboration via the family's relational lens and ways that make them feel most comfortable. Elements of this includes working with parents in nontraditional ways and recognizing life circumstances that prohibit attendance and in-person participation. Natural extensions within the PBS team could include culturally responsive universal teaching regarding the uniqueness of all students and the benefits of learning to embrace individualities.

\section{Limitations and Future Directions-}

There are several limitations of the present study that should be noted. First, the parent participants were engaged on their own volition and did not represent the full scope of parent partnering across all parents engaged within the two case study sites. Secondly the parent participants did not disclose student learning histories and past behavioral health nuances that could speak to the depth and breadth of necessary supports that could or did impact their level of need at each of the PBS tiers of support. The narrow scope of parent participants and the finite description of their experiences shared through the qualitative interviews serves as an 
implication for further studies that delve deeper into specific systemic needs of the school that could span far beyond the intent of effective parent engagement.

Future directions might include the opportunity to further study parent engagement within several schools currently utilizing PBS. The study should include a larger population of parents, varying demographics, and differing implementation levels of the PBS model. Within this study the possible utilization of Epstein's Six Types of Involvement could serve as the analytic lens probing the parent's personal perception of where they fall on the engagement continuum and whether this impression aligns with the school's viewpoint.

\section{Conclusions-}

Findings from this study support the benefits of common voice and unified teaching across the home and school with regard to PBS and positive school climate tenets. Authentic inclusion of parents in this process communicates value to parent perspectives and also the undeniable influence they have on shaping their child's behavioral repertoire and their evolving investment in school-based tasks. Positive behaviors and core values are at the heart of PBS and to effectively emulate that type of priority active partnering and sincere connection must be maximized and optimized for sustained impact and visible behavioral change. Creative rapport tactics and continual communication links foster predictable engagement and invite increased participation beyond the scope of typical academic status monitoring. The intrinsic sense of knowing that you and your child are understood and valued regardless of the behavioral circumstance burgeons relational interactions and extends behavioral teaching and instruction to collaborative partnering that holds a heart-based affective component that superficial resource exchanges and informational sharing undeniably fails to deliver. 


\section{References}

Auerbach, C., \& Silverstein, L. (2003). An introduction to coding and analysis. New York, NY: University Press.

Balfanz, R., Byrnes, V., \& Fox, J. (2013). Sent home and put off-track: The antecedents, disproportionalities, and consequences of being suspended in ninth grade. Disparities in School Discipline. 1-18.

Catsambis, S. (2001). Expanding knowledge of parental involvement in children's secondary education: Connections with high school seniors' success. Social Psychology of Education, 5, 149-177.

Cramer, E. D., \& Bennett, K. D. (2015). Implementing Culturally Responsive Positive Behavior Interventions and Supports in the Middle School Classrooms. Middle School Journal, 46, 1-8.

Creswell, J. (1998). Qualitative inquiry and research design: Choosing among five traditions. London: Sage.

Eccles, J. S., \& Harold, R. D. (1996). Family involvement in children's and adolescent's schooling. Family-School Links, 53, 3-34.

Epstein, J. (1984). School policy and parent involvement: Research results. Educational Horizons, 62, 70-72.

Epstein, J. L. (2002). School, family, and community partnerships: Your handbook for action. Thousand Oaks, CA: Corwin Press.

Epstein, J., Sanders, M. G., Salmas, K., Simon, B., VanVoorhis, F., \& Jansorn, N. (2002). School, family, and community partnerships: Your handbook for action. ( $2^{\text {nd }}$ ed.).

Thousand Oaks, CA: Corwin Press.

Epstein, J. L. (2005). A case study of the partnership schools comprehensive school reform (CSR) model. The Elementary School Journal, 106, 151-170.

Fallon, I. M., O’Keefe, B. V., \& Sugai, G. (2012). Consideration of culture and contest in school wide positive behavior support: A review of current literature. Journal of Positive Behavior Interventions, 14 (4), 209-219.

Glesne, C. (2003). Becoming qualitative researchers: An introduction. Boston, MA: Pearson. 
Henderson, A. T., \& Mapp, K. L. (2002). A new wave of evidence: The impact of school, family, and community connections on student achievement. Austin, TX: Southwest Educational Development Laboratory.

Jaffee, W. B., \& D'Zurilla, T. J. (2003). Adolescent problem solving, parent problem solving, and externalizing behaviors in adolescents. Behavior Therapy, 34, 295-311.

Jenkins, R. R., \& Hutchinson, J. G. (1996). The public health model for violence prevention: A partnership in medicine and education. Journal of Negro Education, 65 (3), 255-266.

Kerbow, D., \& Bernhardt, A. (1993). Parent intervention in the school: The context of minority involvement. Boulder, CO: Westview.

Koegel, L. K., Koegel, R. L., \& Dunlap, G. (1996). Positive behavior support: Including people with difficult behavior in the community. Baltimore, MD: Brookes.

Marshall, J. K., \& Mirenda, P. (2002). Parent-professional collaboration for positive behavior support in the home. Focus on Autism and Other Developmental Disabilities. 17(4), 216-228.

McIntosh, K., Flannery, K. B., Sugai, G., Braun, D. H., \& Cochrane, K. L. (2008). Relationships between academics and problem behavior in the transition from middle to high school. Journal of Positive Behavior Interventions, 1 (4), 243-255.

Merriam, S. B. (1998). Qualitative research and case study applications in education: Revised and expanded from case study research in education. San Francisco, CA: Jossey-Bass.

Merriam, S. B. (1988). Case study research in education: A qualitative approach. San Francisco, CA: Jossey-Bass.

Minke, K. M., Anderson, K. J. (2005). Family-school collaboration and positive behavior support. Journal of Positive Behavior Interventions, 7(3), 181-185.

Nunez, Saurez, Rosario, Vallejo, Epstein (2015). The relationship between perceived parent involvement in homework, student homework behaviors, and academic achievement: Differences among elementary, junior high, and high school students. Metacognition and learning, 10, 375-406.

Parent engagement in schools. (2015, September). Retrieved from https://www.cdc.gov/healthyyouth/protective/parent engagement.html

Patton, M. (1990). Qualitative evaluation and research methods (2 $\left.{ }^{\text {nd }}\right)$. Newbury Park: Sage. 
Schwandt, T. (2001). Dictionary of qualitative inquiry (2nd ed). Thousand Oaks, CA: Sage Publications.

Smolkowski, K., Seeley, J. R., Gau, J. M., Dishion, T. T., Stormshak, E. A., Moore, K. J. Falkensten, C. A., Fosco, G. M., \& Garbacz, A. (2017). Effectiveness evaluation of the Positive Family Support Intervention: a three tiered public health delivery model for Middle Schools. Journal of School Psychology. 62, 103-125.

Sugai, G., Horner, R., \& Todd, A. (2009). PBIS Self-assessment survey. Retrieved from https://www.pbisapps.org

Vargas, J. S. (2009). Behavior analysis for effective teaching. New York, NY: Routledge. 


\section{Appendix A}

1. How did you participate in Positive Behavior Support?

(Possible prompt if needed):

a. Tell me more about what you wanted to learn.

b. Tell me about ways that you would like to extend this learning.

2. What benefits did you receive from participating?

(Possible prompt if needed):

a. Can you give me a specific example how that benefit came about?

3. What challenges did you face?

(Possible prompt if needed):

a. Tell me more about how they affected your family and/or home.

4. What changes, if any, did you see in your child's behavior afterward?

(Possible prompt if needed):

a. Tell me more about those specific changes

b. What impact did these changes have?

5. How do you think these changes came about?

(Possible prompt if needed):

a. Explain that to me in more detail.

b. Do you think there are any other things that caused these changes?

6. How did you engage with your school?

(Possible prompt if needed):

a. Can you give me specific examples of your types of engagement?

b. Can you give me specific examples of why you chose this form of engagement?

7. How did you communicate with your respective school regarding PBS?

a. What do you feel was the most effective form of communication?

b. What did you feel was the least effective form of communication?

c. What types of communication do you feel the school could add to the PBS process that would make you feel more involved as a parent? 


\section{Appendix B}

1. What was your rationale for initiating PBS within your middle school setting?

a. Can you describe for me what was happening within student behavioral conduct to justify this schoolwide PBS intervention?

2. What resources did you allocate to prioritize parent involvement with PBS implementation?

a. How did that affect the overall climate within the school?

b. (prompt if needed) Can you provide me with some examples of that?

3. As an administrator can you describe some of the benefits and challenges you've encountered while implementing PBS with regard to teacher buy-in, academics, parent involvement, and community partnerships?

4. Now that PBS is in place and you've reached fidelity status; how would you describe your vision for change?

5. How do you plan on sustaining both PBS success and also further increasing parent involvement? 